\title{
Research on the Behavior and Strategies of Individual Investors in China
}

\author{
Li Pinjie \\ International Business School. \\ Shaanxi Normal University, SNNU \\ Xi'an, China \\ E-mail:277528319@qq.com
}

\begin{abstract}
This essay was written to observe how investors make decisions. We design the questionnaire on the Internet and collect the answers. The results suggest that investors in the stock market always be overconfident and have bias. In consequence, they usually trade frequently and make irrational decisions. We make some suggestions to the investors to avoid the bias and overconfidence at last.
\end{abstract}

Keywords-Behavioral finance; Stock markets; Investor; Strategy

\section{INTRODUCTION}

The traditional finance paradigm, which is based on the model in which agents are rational, seeks to explain the operation of the securities market in an idealistic way. Unfortunately, during the decades' development of the financial markets, it has become clear that the performances of the individual trading behaviors are not easily understood in this framework. As a new subject, behavioral finance has made systematically explanation on the market abnormal behaviors and makes the challenge to the mainstream theory. With the help of the theory of cognitive psychology, the research on the individual performances can be divided into two parts: the process of belief formation and the process of decision formation.

\section{THEORY OF INDIVIDUAL INVESTORS' BEHAVIORS}

Overconfidence. A large number of experimental results indicate that agents would be more confident than they should be when facing the judgments. It may be the most stable psychological characteristics of human beings, leading investors to take more risks and deviate from the track of rational behavior. As a result, agents would consider the trend predictable regardless of the random factors.

Optimism and wishful thinking. Most people show unrealistic expectations about their capabilities and prospects. They also show the systematically planned delay: they predict that the task will be completed faster than it is.

Cognitive biases. It would be represented when people estimate the probabilities of the events. They usually make judgments relying on the cognition and knowledge.

Representative biases. Representativeness heuristic is often used to help people assess the probability of a dataset which is generated by another model. But it can cause some biases.

\section{THE CHARACTERS OF THE INVESTORS IN CHINA}

A. Retail investors make up the major

In China's stock market, the number of stock trading accounts held by individual investors is dominant. As of February 2016, there were 10,161,800 investor accounts, of which the number of individual investor accounts was $101,320,900$, accounting for $99.71 \%$, and the number of institutional investor accounts was 289,900 , accounting for $0.29 \%$.

The performance of the stock price would be influenced greatly by the individual investors.

\section{B. Turnover ratio is extraordinary high}

The turnover ratio is the percentage of a mutual fund or other investment's holdings that have been replaced in a given year, which varies by the type of mutual fund, its investment objective and/or the portfolio manager's investing style. The turnover rate of SSE A shares were 158.80, and B shares were 88.14. Most of them between 500-10001.

The value is much higher than the securities market in developed countries, and it also indicates such a fact that China's securities market is still immature, and many aspects still need to be improved.

\section{The authorities' policies will have a huge impact on the stock market.}

Unlike other developed countries in the world, the various economic and administrative policies promulgated by the government have a huge guiding effect on stock performance. The information of the policies indicates orientation and resource support, which is necessary for the development of the industry. It will affect investors' expectations of the development prospects of the company or industry, and thus affect the stock price.

1 Shanghai Stock Exchange Statistics Annual(2017), Shanghai Stock change 


\section{RESEARCH ON THE BEHAVIORS OF CHINA's STOCKHOLDERS}

A questionnaire was designed to research the relationship between the characters of investors and behaviors. Some questions $(\mathrm{Q})$ were asked to the interviewees. 126 papers were collected.

\section{A. Education background}

With the development of China's stock market, the intellectual reserve and education level of individual investors are gradually rising. Most of the investors have higher education 2 . The following is an experience about the relationship between the level of education investors have received and the tendency of overconfidence. According to the theory, the turnover ratio indicates the psychological character.

Question 1: Which level of education do you have?
A. Under Middle Education
B. Middle Education
C. Higher Education
D. Bachelor or higher

Question 2: How long will you turnover your stocks in hand?
A. 5 10 days
B. 10 20 days
C. A month $\sim$ three months
D. Three months or longer

The following is the result of the research:

TABLE I. THE RESULT OF THE RELATIONSHIP BETWEEN EDUCATION AND OVERCONFIDENCE

\begin{tabular}{|c|c|c|c|c|c|}
\hline $\begin{array}{c}\text { Ques.1 } \\
\text { Ques.2 }\end{array}$ & $A$ & $\boldsymbol{B}$ & $\boldsymbol{C}$ & $\boldsymbol{D}$ & total \\
\hline $\boldsymbol{A}$ & 1 & 7 & 3 & 2 & 13 \\
\hline $\boldsymbol{B}$ & 14 & 19 & 6 & 2 & 41 \\
\hline $\boldsymbol{C}$ & 16 & 17 & 8 & 2 & 43 \\
\hline $\boldsymbol{D}$ & 3 & 12 & 6 & 8 & 29 \\
\hline total & 34 & 55 & 23 & 14 & 126 \\
\hline
\end{tabular}

According to the table above, investors which are less educated tend to be more cautious. On the contrary, investors with a certain degree of higher education would regard themselves professional agents and will turn over the stocks more frequently. Those who have received master's training have more awe of the stock market because they have more knowledge reserves and more understanding of their own abilities.

\section{B. Industry in which investors are engaged}

The industry in which the investor is engaged will bring him some cognitive bias. The following is a questionnaire about the relationship between the overconfidence and the industries.

Question 3: To what extent is the industry in which you work related to the stock market?

2 Shanghai Stock Exchange Statistics Annual (2016), Shanghai Stock change
A. irrelevant
B. much relevant
C. fully related

TABLE II. THE RESULT OF THE RELATIONSHIP BETWEEN INDUSTRY AND OVERCONFIDENCE

\begin{tabular}{|c|c|c|c|c|c|}
\hline Q2 & $\boldsymbol{A 3}$ & $\boldsymbol{B}$ & $\boldsymbol{C}$ & $\boldsymbol{D}$ & total \\
\hline $\boldsymbol{A}$ & 8 & 17 & 7 & 3 & 35 \\
\hline $\boldsymbol{B}$ & 13 & 23 & 5 & 2 & 43 \\
\hline $\boldsymbol{C}$ & 9 & 10 & 4 & 1 & 24 \\
\hline $\boldsymbol{D}$ & 3 & 7 & 12 & 2 & 24 \\
\hline total & 33 & 57 & 28 & 8 & 126 \\
\hline
\end{tabular}

According to the table above. Investors in the stock market-related industries have more financial knowledge, more inclined to think that they have mastered the trend of market operation, consequently there is a higher turnover rate.

\section{History of the performance of stock}

The following experiment shows the relationship people would consider between the historic performance and the future.

Question 4: Suppose you have a stock that is making a profit. Do you think it will continue to be profitable in the future?
A. Probably yes
B. Probably no
C. Need more analysis
A. Probably yes
B. Probably no
C. Need more analysis

Question 5: Suppose you have a stock that is losing money. Do you think it will continue to lose money in the future?

TABLE III. THE RESULT OF THE RELATIONSHIP BETWEEN HISTORY AND PERSPECTIVE OF THE INVESTORS

\begin{tabular}{|c|c|c|c|c|}
\hline Q5 & $\boldsymbol{A 4}$ & $\boldsymbol{B}$ & $\boldsymbol{C}$ & total \\
\hline $\boldsymbol{A}$ & 35 & 30 & 0 & 65 \\
\hline $\boldsymbol{B}$ & 13 & 24 & 0 & 37 \\
\hline $\boldsymbol{C}$ & 0 & 0 & 24 & 24 \\
\hline total & 48 & 54 & 24 & 126 \\
\hline
\end{tabular}

Through the analysis of the above results we can conclude that for stocks that are making a profit, people usually hold the opinion that they will continue to make profits in the future. On the one hand, the benefits of stocks provide more confidence in their judgment and choice. On the other hand, the historical price of stocks will also give them some reference.

In addition, there are differences in the future expectations of stocks that are making money and stocks that are losing money. On the one hand, people have some luck with the 
accounts that are losing money. They will think that maybe the price will go up in the future.

\section{The attribution bias}

Question 6: If you have stocks that are making a profit, what do you think is the cause?
A. Outstanding ability
B. Luck
C. The stock market is improving

Question 7: If you have a stock that is losing money, what would you think is the cause?
A. Insufficient ability
B. Bad luck
C. The overall downturn in the stock market

TABLE IV. THE RESULT OF THE ATTRIBUTION

\begin{tabular}{|c|c|c|c|c|}
\hline Q6 & $\boldsymbol{A}$ & $\boldsymbol{B}$ & $\boldsymbol{C}$ & total \\
\hline $\boldsymbol{A}$ & 8 & 27 & 14 & 49 \\
\hline $\boldsymbol{B}$ & 18 & 19 & 21 & 48 \\
\hline $\boldsymbol{C}$ & 6 & 7 & 16 & 29 \\
\hline total & 32 & 43 & 51 & 126 \\
\hline
\end{tabular}

Investors often attribute their earnings to their rational judgment, stock picking ability and failure to systemic risks or other environmental factors that cannot be eliminated by the entire capital market. They are not their own judgment errors, and their own ability assessment is unreasonable.

\section{SUGGESTIONS FOR THE INVESTORS IN CHINA's MARKET}

\section{A. Pay attention to technical analysis}

According to the current situation of China's stock market, information is not well represented in market prices. The speculative psychology of investors is too heavy, and the information of listed companies is opaque. The market thus shaped is not an effective market. Because prices cannot reflect all Information, investors can adopt a technical analysis of investment strategies, focus on transaction volume and transaction price, and at the same time conduct a comprehensive analysis of support line \& resistance line and moving an average line, especially for projects with investment value of different price points and stocks. Analysis, to ensure that the support structure and resistance parameters are more in line with the standard, effectively meet the sales psychology, achieve balance control, and ensure the integrity of the treatment effect.

\section{B. The cost-average strategy}

The cost-average strategy refers to the low-cost investment strategy adopted by investors to avoid the huge risk of one-time investment. The cost will be lower than the average price of the stock because of the amount of stocks that investors can buy at each stage is fixed, and the stock type can be either one type or several types. When the stock price falls, the purchase quantity is more. When the stock price increases, the number is relatively small, in general, the number of low-priced stocks of securities investors is more than that of high-priced stocks.

It allows the average price of stocks purchased during a certain period of time to be lower than the average price of all stocks purchased.

\section{The momentum trading strategy}

The momentum trading strategy refers to the investor's prior filtering rules for stock returns and their trading volume. When the stock returns and their trading volume are in line with the established filtering criteria, the investors will sell or buy the stocks. Based on behavioral finance theory, investors are required to take into account the continuity of the intermediate returns of stock prices in the securities market when adopting momentum trading strategies.

\section{The time decentralization strategy}

The time decentralization strategy emerged with the continuous development of financial theory. It is a strategy to spread stock risk through time. Behavioral finance theory believes that with the continuous increase of investment period, the risk of the securities market will gradually decline, which provides an effective reference for the investment entities in the securities market when making investment decisions, but the time diversification strategy cannot be used frequently, otherwise it is very It is easy to cause irrationality of investment behavior.

\section{E. Behavior control strategy}

The behavior control strategy is actually to control the investor's investment loss in the investment process because of his own greed or fear. This kind of investment strategy is more binding and mandatory for investors' actual investment behavior. In view of the current unstable stock market situation in China, the current behavioral bias of investors can basically make effective contributions to their own investment behavior through behavior control strategies. Beam and control, which promotes more standardized investment behavior and improves investment yield.

\section{CONCLUSION}

According to the collection and analysis of the results of the questionnaire, we can draw the following conclusions : First, more attention should be payed to technical analysis, second, some measures need to be taken to control the behaviors. At last, more strategies can be developed to spread risk and reduce costs.

\section{REFERENCES}

[1] Barberis, Nicholas, and Richard Thaler. "A survey of behavioral finance," Handbook of the Economics of Finance 1 (2003): 1053-1128.

[2] Tversky, Amos, and Daniel Kahneman. "Judgment under uncertainty: Heuristics and biases," science 185.4157 (1974): 1124-1131.

[3] Kim, Kenneth A, and John R. Nofsinger, "The Behavior and Performance of Individua1 Investors in Japan,’Working Paper, 2002.

[4] De Bondt, W. F. M. and Richard H.Thaler, "Does the stock market overreact?" Journal of Finance 40, 793- 808, 1985

[5] Odean, Terrance, "Do investors trade too much," American Economic Review 89, 1279- 1298, 1999. 